\title{
EDITORIAL
}

\section{CHANTAJE COLONIAL E ILEGITIMIDAD INSTITUCIONAL OCCIDENTAL. LA VIGENCIA DE LO COMÚN EN LA REGIÓN LATINOAMERICANA}

\author{
COLONIAL BLACKMAIL AND WESTERN INSTITUTIONAL \\ ILLEGITIMACY. THE VALIDITY OF THE COMMON \\ IN THE LATIN AMERICAN REGION
}

EDISON VILLA HOLGUÍN*

Recibido: 20 de mayo de 2019 - Aceptado: 15 de junio de 2019 -

Publicado: 30 de julio de 2019

DOI: $10.24142 /$ raju.v14n28a1

El desarrollo ha llegado a ser indispensable para las economías, pero es insostenible tanto para el individuo como para la humanidad entera... La tasa de crecimiento del capital no rinde cuentas, sobre los procesos de degradación de nuestra civilización

(Morin, 1998)

\section{Resumen}

Esta reflexión pretende visualizar algunos elementos y características de lo que se ha nombrado actualmente como el agotamiento de la racionalidad constitutiva de lo que fue conocido como "el proyecto

* Licenciado en Educación, Universidad de Antioquia; Magíster en Educación, Universidad de Medellín; candidato a Doctor en Didáctica de la Conciencia Histórica, IPECAL, México. Docente de Humanidades e investigador social grupo Interuniversitario Kavilando. Coordinador Unidad de Investigación Academia Superior de Artes. Correo electrónico: interandinos1@gmail.com 
político de la modernidad". Para el caso latinoamericano, la institucionalidad política, acuñada al sistema democrático de occidente, en lugar de ser solución termina agudizando el contexto de dominación e injusticia. Al presente, "las repúblicas democráticas", en la región latinoamericana, no han sido los espacios esperados de trámite de las contradicciones del propio sistema. El siguiente argumento, en perspectiva crítica, intenta aportar al actual debate político nombrando algunos desafíos para las teorías políticas que buscan superar el pensamiento único, hoy reducido al economicismo hegemónico que hace ilegítimo el estado, en la búsqueda de otros proyectos de sociedad para el siglo XXI.

Palabras clave: racionalidad, modernidad, repúblicas democráticas, contradicciones del sistema, teorías políticas.

\section{Abstract}

This reflection aims to visualize some elements and characteristics of what has been named today as the exhaustion of the constitutive rationality of what was known as "the political project of modernity". For the Latin American case, the political institutionality coined to the democratic system of the West, instead of being a solution, ends up sharpening the context of domination and injustice. At present "the democratic republics" in the Latin American region, have not been the expected spaces for processing the contradictions of the system itself. The following argument in critical perspective, tries to contribute to the current political debate, naming some challenges for political theories that seek to overcome the unique thought, today reduced to the hegemonic economism that makes the state illegitimate, in the search of other projects of society for the $21^{\text {st }}$ century.

Keywords: Rationality, modernity, democratic republics, contradictions of the system, political theories. 


\section{INTRODUCCIÓN}

Por medios ilustrados, la sociedad burguesa de la Europa del siglo XVIII, y quienes en el mundo pensaban como ella, con la promesa de garantías de libertad y trato en igualdad y fraternidad, convinieron un pacto político bajo el que pretendieron que el destino de su sociedad quedara en manos de ella misma, fundando el hito idealista de una cultura cívica, democrática y una sociedad igualitaria de compromiso común, donde se manifiesta la sujeción a la ley por parte de la sociedad civil.

La idea de un mundo "moderno" se afianza, como es sabido, en la polémica francesa entre los anciens y los modernes, a finales del siglo XVII. Alrededor de esta polémica se constituyen la idea ilustrada del progreso, que será un elemento central de la filosofía política e histórica del siglo XVIII, y la definición de la sociedad como un sistema perfectible, que se sujeta progresivamente a paradigmas más racionales de acción (Melo, 1990, p. 1).

La modernidad se convierte así en el proyecto sociopolítico donde la razón humana termina dando legitimidad a los regímenes occidentales que asumen como fundamento "el contrato social" y las "democracias liberales".

Algunos análisis contemporáneos asumen que la sociedad occidental está llegando a los límites de su racionalidad, en términos de sus modelos de administración política, fenómeno que se nombró como "la crisis del estado moderno", que consiste en delegar el poder y las decisiones de los estados-nación a los intereses de las redes de comercio de las superpotencias. A dicha pérdida de soberanía se le suma la imposibilidad de resolver los problemas profundos de lo humano, desde el equilibrio igualdad-libertad; además de la omisión a un trámite adecuado de las agudas problemáticas sociales como el empleo, la alimentación, la vivienda y la salud de las mayorías, situaciones que lo hacen inviable e ilegítimo.

El estado-nación, al quedar caduco como formato o lugar para tramitar la complejidad de los conflictos socioculturales e históricos, generados por la linealidad de la ley del mercado y su idea de progreso, deja la puerta abierta a nuevas institucionalidades multinacionales que se relevan y disputan el poder político. Hoy parece ser que el comercio a gran escala es el promotor del cuidado y la regulación de los bienes comunes y las garantías para la vida, nombradas por algunos como "derechos humanos", a través 
del modelo de servicios, siendo el capitalismo de la época quien da lugar a una nueva infraestructura que termina disponiendo de los espacios políticos y de la demanda social de las poblaciones humanas, operado, eso sí, por las hegemonías globales desde grandes centros administrativos de registro y control tecnológico.

En Latinoamérica, los aparatos legales no pueden resolver las demandas y deudas sociales e históricas. Las ataduras radicalizadas a la inversión de capitales externos e internos, el tecnicismo normativo a la medida de las clientelas de la contratación estatal y la custodia del poder militar oficial, al beneficio privado, no posibilitan la participación política "democrática" de actores, organizaciones y movimientos sociales que han luchado históricamente por los derechos con propuestas y alternativas de trámite a los problemas concretos y comunes de las mayorías de la población. Esta lectura de la realidad del contexto político actual implica incluir en los análisis, además de lo evidente de los padecimientos sociales o consecuencias, lo que normalmente no consideramos o normalizamos, es decir, sus causas, que no son otras que la riqueza y tierra concentrada, la privatización de las garantías sociales y la guerra por el dominio de los recursos, elementos que fundamentan un esquema de relación sustentado en la adquisición de capital a partir del despojo.

\section{A MODO DE CONTEXTUALIZACIÓN}

El estado occidental es configurado en el pensamiento político del siglo XVII y perfeccionado en los siglos siguientes como la institución que encarna los fines comunes de sus asociados, según el pacto celebrado y al que los socios se atienen: "que cada quien esté dispuesto a hacer cesación de su derecho cuando los demás estén también dispuestos a hacerlo, en una cesión general de derechos" (Hobbes, 1989, p. 51). "Todos los hombres que pueden afectarse recíprocamente deben estar dentro de la jurisdicción de alguna institución civil" (Kant, 1933, p. 90).

Un siglo después, nace una segunda versión del contrato, constituyéndose un estado restringido, sometido a los desafíos del industrialismo, sustentado en el derecho que preserva y garantiza la autonomía del individuo, pero solo en lo que tiene que ver con la participación en el mercado, ignorando el mínimo principio de supervivencia de la especie. 
La tecnología occidental y la gente que la ha empleado, han constituido las fuerzas más destructivas de la historia humana. Ningún desastre natural ha destruido en tamaña magnitud. Ni siquiera la Era Glacial tuvo tantas víctimas... A medida que avanzó la segunda mitad del siglo Xx la gente de Occidente pasó a buscar otras fuentes de energía con que alimentar su tecnología. Sus ojos se han posado en la energía atómica, una forma de producción energética cuyos subproductos son las sustancias más ponzoñosas que el hombre haya conocido jamás (Akwesasne Notes, 1977, p. 39).

El hito industrial y tecnológico vivido en el siglo Xx termina transformando el contrato social y sus principios de igualdad y libertad en el marco del derecho privado, reviviendo el modelo de sociedad prescrita; pero esta vez el dios capital lo decide todo.

Hoy la especie humana se enfrenta al problema de su propia supervivencia. El estilo de vida conocido como Civilización Occidental está en una senda mortal para el que su propia cultura carece de respuestas viables. Cuando se enfrenta con la realidad de su propia destructividad, solo atina a avanzar a terrenos de destrucción más eficientes. La aparición del plutonio en este planeta es la más clara de las señales de que nuestra especie está en dificultades. Es una señal que muchos occidentales han preferido ignorar (Akwesasne Notes, 1977, p. 39).

Las aspiraciones fruto del pensar de la humanidad ilustrada, que recogió las tensiones y conflictividades de la época, produjo la sociedad ideal del consenso, con intereses altruistas y nobles, pero cuyo desarrollo histórico, por lo artificioso y ficcionado, terminó siendo el pretexto para imponer una racionalidad única, blanca, burguesa, masculina, cristiana, antropocéntrica y prescrita entendida como la vía política correcta.

Hasta ahora en los Andes se habla indistintamente de "cristianos" como sinónimo de "humanos", como el occidental no alcanza a distinguir "humanos" dentro de "el espejo andino", o no ve "individuos" en las comunidades andinas, esto lo lleva a continuar su labor "cristianizadora" o de convertir a los andinos comuneros en individuos occidentales (Todorov, 1987, p. 14). 
El pensamiento de corte crítico describe la democracia contemporánea como una relación de complicidad entre fuerzas de producción y los poderes públicos, que se hace entender como modelo definitivo de organización de las sociedades humanas por parte de unas minorías determinadoras y acumuladoras de capital, sin preocuparse por las situaciones de miseria y exclusión social que padece la mayor parte de la población, siendo el poco célebre "fin de la historia" el guion político con el que se opera desde la colonizada dirigencia latinoamericana de orilla neoliberal; idealización que hace creer que la

democracia liberal es la única aspiración política coherente que abarca las diferentes culturas y regiones del planeta. Además, los principios liberales en economía —el "mercado libre"- se han extendido y han conseguido producir niveles sin precedentes de prosperidad material, lo mismo en países industrialmente desarrollados que en países que al terminar la Segunda Guerra Mundial formaban parte del Tercer Mundo (Fukuyama, 1989, p. 14).

Hoy, la mayoría de la población latinoamericana, por desinformación o desconocimiento, vive al margen de perspectivas humanistas o emancipadoras. Una minoría intelectual trata de pervivir desde un reducido espacio académico, buscando que la opinión pública enfoque, críticamente, el funcionamiento del actual modelo de estado; y como diría Alberto Lettieri (2005), desde allí advertir sobre:

Los límites del "productivismo", para que el desarrollo de la economía no se haga a expensas del derecho de las futuras generaciones a una vida saludable en el planeta (algunos dirán: del derecho de la propia naturaleza, de la propia Tierra), a las críticas a la licuación de los valores de la solidaridad y la integración social en manos de la locura consumista a la que nos lleva el desarrollo de un capitalismo desaprensivo y cada vez más inhumano (p. 24).

\section{A MODO DE DESARROLLO}

\section{El caso de la autodeterminación desde el latinoamericanismo}

Los paradigmas universales de salvación siguen una línea de disputa hegemónica por el dominio planetario, manteniendo en jaque su "desarro- 
llismo" y las formas de la producción global del siglo XXI. Pero la capacidad para promocionar y consolidar el cambio social en el marco de la igualdad y la justicia social depende de algo más que de la supuesta legitimidad del formato democrático occidental; allí el peso recae sobre el acumulado de dignidad y la fuerza orgánica de los movimientos populares, como escenario referente de construcción y transformación social. Decía el filósofo mexicano Leopoldo Sea (s. d.), que en

la necesidad que tengan los latinoamericanos de ser capaces de explotar y usufructuar sus propias riquezas, de la misma forma que les era necesario no caer más en "el suelo de seres que no somos", siguiendo "ideales educativos que lejos de formarnos nos deforman" o "imitando un mundo que nos es ajeno, con descuido de lo que nos es propio". Explica también cómo el maestro se oponía a la "América deslatinizada", a la América ajena a su destino, un destino que de una u otra manera le ha marcado su propia e innegable historia

El chantaje comercial del norte y la herencia colonial del belicismo perpetúa la sistemática linealidad desarrollista en la región. Durante el siglo $\mathrm{XX}$, las geoestrategias de la política imperial de los siglos anteriores obstaculizaron los propios desarrollos regionales y determinaron las categorías universales con las que los pueblos latinoamericanos tendrían que pensarse, sin ser consideradas sus condiciones históricas, sociales y culturales. Fue a esto que se le nombró como modelo de dependencia en América. Según el argentino Claudio Katz, el texto la Teoría de la dependencia de 1968 surge como: "interpretación del subdesarrollo centrada en la pérdida de recursos padecida por la periferia. Donde se ilustró especialmente cómo la reproducción dependiente acentuaba la inserción internacional subordinada de la región" (Katz, 2018, s. p.).

El decadente modelo estatal de occidente ha sobreentendido a los pueblos latinoamericanos como sociedades disfuncionales o "estados subdesarrollados". La modernidad, como camino trazado desde el colonialismo, generó pueblos presionados por la productividad occidental, que han reproducido la dependencia económica y el instrumentalismo de los estados locales en función de la inversión extranjera y la gobernabilidad de "pseudo-democracia" que les caracteriza.

El gran error había sido también el de "nuestros emancipadores mentales en el pasado siglo" que creyeron en la posibilidad de los pueblos 
americanos a "renunciar a su modo de ser propio, para ser otro"... Bolívar había prevenido de esta América... "que en vano trataría de ser semejante a la que se le presentaba como modelo a realizar" (Zea citado por Sierra, 1992, p. 36)

En los últimos cincuenta años en la región, los movimientos sociales clásicos, a partir del paradigma proletario, en formato de partido o sindicato, enfocaron y desgastaron grandes posibilidades de cambio político desde el modelo administrativo occidental; es decir, se pasa de la esencia de la revolución desde abajo a la agencia de la democracia vía derechos humanos. Hoy estos se encuentran anclados al proyecto ilustrado del norte, en una especie de alienación por llegar a la modernidad.

Las estrategias de muchos de los repertorios de acción colectiva de los movimientos sociales son sancionadas y castigadas bajo el argumento de actuar fuera de la ley. Al definir los requisitos para la ciudadanía y los derechos de los ciudadanos frente al poder del Estado, el cuerpo político determina quién puede participar y de qué forma, estipulando el tipo de asociaciones que la gente puede formar: partidos, sindicatos, asociaciones civiles, etcétera; y además define aquellas que están implícitamente prohibidas (por ejemplo, las guerrillas) (Favela, 1995, p. 95).

Por otro lado, en la historia reciente latinoamericana, en perspectiva "progresista" o de búsqueda social desde el formato democrático, algunos gobiernos, al irse ocupando de las incertidumbres y contradicciones heredadas en las nuevas subjetividades o ciudadanías críticas y en diversidad, de acuerdo con su realidad contextual, abordan y profundizan en la tensión de modificar y replantear su propio modelo político a partir del principio de diversidad, implementando algunas iniciativas de cambio, donde la multiculturalidad empieza a hacer presencia.

[Un] aporte de los movimientos sociales es su contribución a la pluralidad de ideas en el debate público desde los diferentes temas que defienden desde su identidad (por ejemplo, la cuestión indígena, el movimiento feminista o el movimiento lésbico-gay). Dicha incorporación tiene igualmente la posibilidad de la institucionalización del discurso en la agenda legislativa y la transmisión de valores y repertorios culturales en las prácticas sociales (Zamora, 2016, p. 18). 
De otras maneras, en las esferas de lo social-popular y la praxis comunitaria, pobladores, andinos, costeros, isleños y rivereños de la Latinoamérica profunda, en el presente, luchan por un nuevo proyecto que se ha conformado de manera instituyente para atender a los intereses desde abajo, planteando otras dimensiones de vida económica y cultural de lo político.

\begin{abstract}
[Asumiendo] los problemas de ruptura y disociación de la identidad cultural y del imaginario colectivo en los países latinoamericanos... como consecuencia de los fenómenos coloniales y neocoloniales. Considerando siempre que "el colonialismo mental" era la base de la aceptación de los otros colonialismos que azotaban al continente (Sierra, 1992, p. 39),
\end{abstract}

al intervenir las causas sociales por la vía autonomista, emancipada o autodeterminada, en este intento de superación de la alienación, el embrujo y la ignorancia y la exclusión social y política que genera el decadente sistema democrático occidental, y buscando la cualificación de la población para la participación directa a través de colectivos alternativos. "Devolver al ciudadano su papel fundamental que es el de cómo gobernar su colectivo, su barrio, su ciudad, su nación" (Sierra, 1992, p. 38).

En el entorno regional, el principio de autodeterminación lo vienen liderando los movimientos sociales y populares que ponen en marcha la lucha por nuevas visiones y prácticas de lo político, de acuerdo con las propias capacidades y las posibilidades que da el contexto, generando procesos de cambio desde el colectivismo, en coherencia con las necesidades de sus pueblos y en búsqueda de un desarrollo sustentable para las relaciones humanas y soportable para el ecosistema, convirtiéndose en referentes de cultura política y proyectos de vida. EL MST en Brasil, por ejemplo, desde 1970 hasta la fecha, ha ido consolidando un proyecto de lucha contra el latifundio y el agronegocio, por la reforma agraria popular y por el derecho constitucional de todos los trabajadores rurales de tener tierra y vida digna en el campo. "Una reforma agraria que tiene como base la democratización de la tierra, buscando producir alimentos saludables para toda la población" (Secretaría Nacional del MST, 2013).

En los últimos años, dichas movilizaciones populares, con sus acciones de recuperación territorial y endógena cultural, han aportado en la visualización de los profundos cuestionamientos al sistema de relaciones de opresión política-económica sobre la vida y la diversidad ecosistémica del 
continente. El acercamiento a la acción colectiva y a los planes territoriales de vida, desde la construcción y las luchas de diversidad de pobladores latinoamericanos de los andes y sus reivindicaciones colectivas, dejan entrever propuestas concretas desde categorías como el buen vivir anclado en la justicia social, y proyecciones en el ámbito de lo político que hacen pensar en la vigencia y necesidad de procesos a-modernos o decoloniales, con los cuales se transita en la esperanza de vientos de cambio que implique que nuestra América se sacuda decidiendo el devenir o el propio rumbo. El referente más especial es el de los indígenas zapatistas en México, que luchan desde enero de 1994 hasta el presente por hacer aprobar la ley de derechos y cultura indígena. En palabras de su vocero, el subcomandante Marcos: "Queremos vivir, queremos demostrar que también podemos construir en paz un desafío: el de desarrollarnos como comunidades y no tener que vivir siempre con el estigma de que ser indígena significa ser pobre y vivir en la miseria" ("25 años del levantamiento zapatista en México: el día que el subcomandante Marcos ‘se quitó la capucha' para BBC Mundo”, 2018).

Tanto el MST, el EZLN y los mingueros del sur de Colombia, nos dejan ver una Latinoamérica que se constituye a sí misma al calor de la lucha, a través del compromiso identitario de diversidad de procesos comunitarios que decidieron estar fuera del operativo dominante del estado-nación, y en sus territorios construyen poder y avanzan en democracia radical como proyectos de sociedad, generando la propia coyuntura, dando el paso a las preguntas por la conservación de la biodiversidad, cambiando la escala del paradigma político del desarrollo occidental (Morin, 1985) y su globalización económica. "Nosotros nacimos y hemos vivido ancestralmente acá y gracias a nuestras políticas, y a que tenemos un gobierno propio hemos logrado conservarla" (Paz, 2019).

A partir de la ruptura con Occidente, ese potencial de políticas autodeterminadas dejan ver una Latinoamérica conflictuada y crítica, que pone en constante crisis su internalidad política, donde se agudizan las condiciones en la búsqueda de rehacerse a sí misma como sociedad de todos los colores, en lucha por el cambio de proyecto; planteando un nuevo desafío al mundo político, como lo nombraron los pueblos indígenas zapatistas de Chiapas, en enero de 1994: "El mundo que queremos es uno donde quepan muchos mundos. La patria que construimos es una donde quepan todos los pueblos y sus lenguas, que todos los pasos la caminen, que todos la rían, que la amanezcan todos" (Monsiváis, 1997, p. 15). 


\section{A MODO DE CONCLUSIÓN}

La movilización social como la reserva de defensa, como agente importante de la política de acción, de la voluntad deliberada y la autonomía de los ciudadanos, es una fuerza con capacidad para desactivar paulatinamente la injusticia. Se necesitan echar a andar, como pueblo, acciones deliberadas sobre cómo resguardar los pactos sociales y asegurar la inclusión de las voces de las mayorías, para enfrentar las restricciones neoliberales y para preservar la construcción y el sentido de la pertenencia al proceso de dignidad de los pueblos, que nos permite pensar el derecho que tienen los pueblos a que los dejen vivir en paz, autoorganizándose y construyendo planes de vida en sus territorios. Las organizaciones populares tienen como móvil de acción los intereses colectivos para la promoción y defensa de los bienes comunes y para generar el escenario apropiado para la transformación de las condiciones políticas y sociales. Un sinnúmero de movilizaciones y concentraciones recogen la multiplicidad de expresiones de pobladores en los campos y los centros urbanos, buscando ser escuchados en su lucha por un pacto social que los incluya.

Los movimientos sociales, en la búsqueda de alternativas de solución y respuestas a la restringida democracia, empiezan a configurarse desde poderes alternos y paralelos, favoreciendo la participación comunitaria y popular, consolidando espacios, cualificando el reclamo de los pueblos que demandan la posibilidad de tejer dignidad, derechos, tierras, viviendas y posibilidades de que la vida perdure como colectividad en relación con el equilibrio ecosistémico. Lo organizativo, como proceso que demanda tiempo y capacidad creativa dentro de los movimientos desde abajo, tiene un valor invaluable tanto para la recuperación de la dignidad como sujetos, como para la construcción de la identidad que dé legitimidad a las luchas, que posibilite convertirlas en medio de presión política, que lleve al establecimiento de acuerdos humanitarios y políticos con los regímenes.

La formación popular tiene allí el papel de espacio que trabaje con la conciencia, que active los valores necesarios para superar las relaciones de dominación en el escenario de las prácticas sociales; la apropiación crítica y autocrítica de las propias prácticas políticas y comunitarias, que implica el desarrollo de acciones que busquen que las colectividades logren el reconocimiento de su propia experiencia de transformación organizativa y la proyección de su praxis política en la adversidad de los contextos y territo- 
rios donde accionan. Esa autoproducción de la historicidad es un rasgo esencial hacia el cambio de la propia historia, personal, colectiva y organizativa como región.

Una sociedad mejor que la que tenemos empezará cuando se reconozcan las dificultades para tramitar los conflictos, haciendo énfasis en dos factores condicionantes: la ausencia de cultura política y la incapacidad de negociación política. A partir del trabajo de los movimientos populares Latinoamérica va ganando modificaciones y aperturas institucionales que posibiliten espacios para la participación popular en la negociación y el trámite de los conflictos. Los movimientos y organizaciones generan las coyunturas críticas, es decir, ponen en crisis el establecimiento, obligando a los poderes instituidos y hegemónicos al reconocimiento de las voces desde abajo, como sujetos de una misma comunidad política, que no tienen que eliminarse para generar un logro político.

Allí radica la importancia de cualificar el pensamiento y la cultura política para la interlocución y el diálogo, para que las iniciativas organizativas puedan recoger las capacidades y esperanzas que se han ido acumulando en los procesos de resistencia a las relaciones socioeconómicas y culturales de dominación ejercidas desde la institucionalidad. El establecimiento, como estrategia de captación, trata de adecuarse a las luchas tratando de relegitimar su poder. Los procesos organizativos podrían asumir con cálculo político la apertura de ciertos espacios donde sea posible pactar asuntos como la promoción de una economía de redistribución de riqueza y hacer el seguimiento a tal concertación; igualmente, consolidar los escenarios y procesos de memoria histórica y comisiones de verdad como herramientas que, en la coyuntura de la tensión política, logren mantener el protagonismo de los sujetos y el reconocimiento de su propia experiencia de transformación. 


\section{REFERENCIAS}

Akwesasne Notes (Ed.) (2005). Basic call to consciousness. Nueva York: Native Voices.

Favela, D. (2002). La estructura de oportunidades políticas de los movimientos sociales en sistemas políticos cerrados: examen del caso mexicano. Estudios Sociológicos, 20(1), 91-121.

Fukuyama, F. (1992). El fin de la historia y el último hombre. Buenos Aires: Planeta.

Hobbes, T. (1989). Leviatán. México: Fondo de Cultura Económica.

Kant, I. (1933). La paz perpetua. Madrid: Tecnos.

Katz, C. (2018). América Latina desde la teoría de la dependencia. Conferencia expuesta en el Encuentro "La economía de América Latina y el Caribe ante el nuevo entorno internacional", ANEC, La Habana. Recuperado de https://www.alainet.org/es/articulo/195447

Lettieri, A. (2005). Discutir el presente, imaginar el futuro: la problemática del mundo actual. Buenos Aires: Prometeo Libros.

Melo, J. O. (1990). Algunas consideraciones globales sobre "modernidad" y "modernización" en el caso colombiano. Análisis Político, 10, 23-35.

Monsiváis, C. (1997). Crónica. En EZLN 2 de octubre de 1995 - 24 de enero de 1997. México: Ediciones Era.

Morin, E. (1995). Fronteras de lo político. Revista de Occidente, (168).

Morin, E. (1998). Civilización. Madrid: Tendencias siglo XXI.

Paz, A. J. (2019). Colombia: la minga indígena de Putumayo se reactiva en medio del Paro Nacional. Recuperado de https://es.mongabay. com/2019/04/minga-indigena-putumayo-colombia-y-paro-nacional/

Secretaría Nacional del MST (2013). Programa Agrario del MST. Sao Paulo: Secretaría Nacional del MST.

Sierra, C. de (1992). América, el latinoamericanismo y la política internacional en Marcha (Uruguay). América: Cahiers du CRICCAL, (9-10).

Todorov, T. (1987). La conquista de América. La cuestión del otro. Bogotá: Siglo XXI Editores.

25 años del levantamiento zapatista en México: el día que el subcomandante Marcos "se quitó la capucha" para BBC Mundo (2018). BBC Mundo. Recuperado de https://www.bbc.com/mundo/noticias-america-latina-46317955

Zamora, C. B. (2016). Movimientos sociales, democracia y Estado de Derecho. Una mirada a la contribución de los movimientos sociales a la democratización e institucionalización del Estado de Derecho. Tla-melaua, 9(39), 152-171. 